\title{
THE RISE OF THE HITTITE EMPIRE: A COMPARISON OF THEORIES ON THE ORIGINS OF THE STATE
}

\author{
W. Richard Stephens, Jr. \\ University of Kansus
}

Mid-American Review of Sociology, 1979, Vol. IV. No. I : 39.55

\begin{abstract}
Alternative theories of state development proposed by Carneiro (1970) and Willer (1977) are presented and discussed briefly. Each is considered in terms of its applicability to the development of the Hittite Empire of ancient Turkey. It is concluded that Willer's framework, which allows a central role to factors external to the prevailing system, is more useful for the analysis of the case of the Hittite state and, in general, may have greater scope and predictive ability.
\end{abstract}

\section{INTRODUCTION}

Robert L. Carneiro (1970), in an article entitled, "A Theory of the Origin of the State," gives an interpretation of state development based on data concerning the Mesopotamian, Egyptian, and Central American Empires of antiquity. Several years later, David Willer (1977), in a paper entitled, "A Network Interpretation of Carneiro's Theory of the Origin of the State," proposed an alternative interpretation designed, not to replace, but to complete the examination of state and empire origins. Given these alternative interpretations, it is the intent of this article to present new data and evaluate the applicability of the proposed theories in light of the new data. My intent is not to provide a formal test of the theories, but rather to shed light on their relative scope and precision. Therefore, neither theory will actually be 'proven' or 'disproven'; more accurately, they will be evaluated.

The data to be used in the following evaluation comes from the ancient history of what is now the country of Turkey. From 1900 B.C. to 1200 B.C. there thrived an empire which rivaled the 
Egypt of Ramses UI. The land was called Hatti, the people, Hittites. Only recently has the Hittite story come to light. Consequently, theoretical interpretation of various aspects of the Hittite Empire has not yet taken place. Therefore, the Hittite history is wcll suited for the task at hand.

\section{PRE-STATE ANATOLIA ${ }^{1}$}

In order to fully comprehend the rise of the Hittite state, it is imperative that one understand the system operating prior to state formation. Even before 1900 B.C., Anatolia (Asia Minor) was recognized as a land rich in resources. As would become more and more evident, the variety and volume of its metal deposits was its most significant asset. It was the exploitation and development of these metal deposits which supported the prevailing system and fostered the growth of the state.

Archcological evidence suggests that, as early as 30,000 B.C., raw materials were being transported to areas in which they were scarce. The demand for metals, however, became most acute with the beginnings of horticulture and the domestication of animals around 9000 B.C. Tools were needed to work the ground, and tools of metal proved more efficient and durable than ones made from other materials. However, unless one found himself near a convenient deposit, inferior tools had to be used. Given an agrarian lifestyle, mobility was quite limited, and some system of trade was necessary.

The kingdoms of Mesopotamia were lands rich in agricultural potential, yet lacking in the resources necessary to make them flower. Eventually, a trading network was established which connected various centers on the Anatolias plateau with the civilizations of the Tigris-Euphrates valleys. Evidence supports the presence of specialized trading centers, called kamms, as early as 7000 B.C. These centers, which showed no other means of support, conducted routinized trading operations. Assyrian merchants (the leaders in trade at that time) generally took up full-time residence in these centers and, in some cases, took Anatolian wives. 
The Assyrians and others of Mesopotamia clearly wanted silver, gold, and copper. For these commodities, they traded woolen cloth, manufactured clothing of various types and, most importantly, tin. Tin was the one metal most scarce in Anatolia, as well as the most important to the development of an Anatolian bronze-age economy; tin and copper are necessary for the production of the harder alloy, bronze.

By the latter part of the third millennium B.C., the Anatolian trading system had evolved into a land of small city-states with their rulers living in castles. Their economies were based primarily on agriculture, but their real wealth and inportance resided in metals and metal products. Gurney (1954:19) speculates that before the Hitrites, there were at least ten small principalities in the Anatolian plateau and perhaps cven more. The resulting activity of these city-states and petty kingdoms involved occasional warring activitics with varying degrees of success; alliances were often formed and, here and there, short-lived ententes cordials appeared. But of these, there were none which were successful in concentrating their power and dominating any significant portion of Anatolia. Instead, Anatolian society of the third millennium B.C. was cliaracterized by a number of separate but interdependent principalities.

Until about 1780 B.C., the Assyrian-Anatolian relationship was maintained peacefully. Of utmost importance to this relationship was the maintenance and accessibility of the trade routes by which the goods flowed. However, around 1780 B.C., a people known as the Hurrians had successfully spread actoss northern Mesopotamia toward the Mediterranean and had begun to achieve political supremacy in the states on the upper Tigris and Euphrates and in the hills bordering on southeast Anatolia. As a result, Assyria was cut off from her commercial colonies and her power quickly collapsed. She was soon incorporated into the expanding empire of Hammurabi of Babylon. For the Anatolians, the loss of their tin supplies was similarly disasterous. On the whole, the cities that flourished during the period of the Assyrian merchant-colonies went into a decline from which they were never able to resurrect themselves. The bond which had loosely tied the 
communities was broken, and the resulting isolation of trade-dependent communities and principalities was devasting.

\section{THEORIES ON THE ORIGIN OF THE STATE}

Given the apparent disarray and general depression of the Anatolian principalities, due primarily to the loss of tin supplies, the question concerns how the Hittite Empire arose. That the Hittites became an empire of significance is well documented (see Hicks, 1974), and thus serves as an adequate test of the scope and applicability of the following theories.

\section{Cameiro}

In order to study the origins of the state it is essential to understand what the state is. Accordingly, Carneiro (1970:733-738) defines a state as an autonomous political unit, encompassing many communities within its territory and having a centralized government with power to collect taxes, draft men for work or war, and decrec and enforce laws. Carneiro claims that in general, this did not begin to take place until around 5000 B.C. Three related forces combined to foster state formation: environnental circumscription, resource concentration, and social circumscription.

Environmental circumscription operates where productive land areas are sharply and severely bounded by difficult or nonproductive land. As examples, Carneiro cites river valley empires such as the Valley of Mexico, the Nile Valley, the Indus Vallcy, and Mesopotamia in the Tigris-Euphrates river valleys. In these cases, the river valleys are the only viable alternatives for habitation. Lands outside the valley are not productive, and the difficulty of moving to another valley is prohibitive. The consequence of such circumscription is eventual overcrowding. More land is needed for agricultural production (given the existing state of technology), but duc to population increases, less land is available. Warfare among neighboring settlements over land is the next stcp. The victors incorporate the land into their domain, often sparing the conquered in return for increased production 
efforts achieved through intensification of present methods and some invention. This process is repeated until the entire valley is ruled by one group.

The second force is resource concentration. In this instance, although geographic mobility is not hampered severely, a particular area is seen as being so much more advantageous than any other that people often choose the consequences of overcrowding to the choice of moving away. A potential consequence of such a choice is subjugation and the exaction of a tribute. However, in the long run the decision to stay provides more benefits than a move to a less crowded area. According to Carneiro, resource concentration stimulated the chiefdoms of Amazonia.

Social circumscription provides the third force for state development. The Yanomamo Indians of Venezuela, for example, lived in an extensive region of noncircumseribed rainforest, away from any large river. However in this casc there is no even spread of settlements; rather, the area has a definable core. Consequently, those near the center do not have the same alternatives as those inhabiting the perimeter. A frequent result is that those located in or near the center of the habitated area are, in effect, lorked in by those around them. Overcrowding of the central area results and conflict over land ensues. The results are the same as in the two previous cases; one group effectively dominates the other and exacts a tribute from them.

In short, population density and some form of circumscription, which leads to land scarcity, are the necessary prerequisites for state development. In other words, Carneiro is proposing a wholly intermal description of the process of state development. Counter to this claim is that of David Willer (1977).

\section{willer}

Circumscription, in Willer's argument, is in fact an important aspect. But whereas Carneiro's concern was with population size, Willer examines the possibility and the costs of administering and maintaining a state. The primary variable here is area, specifically, the size of the area to be coerced, administered, and maintained. 
In immediate relation to area is the cost involved in the state process. Thus, as Willer points out, the costs of coercing a population for purposes of taxation are not simply a function of the size of that group, but are more closely related to the size of the area administered. Consequencly, for any given area (and thus for any given cost of coercion), the total product which can be extracted from the population for a given cost of administration of that area increases as the population increases.

Area and cost relationships are made manifest in a number of different ways. Cost efficicncy can be increased through coercion of agriculturalists who practice annual or semi-annual cropping. This allows routinization of taxation and cyclical, rather than continuous, coercion. With the use of cyclical coercion, it is not surprising that the carly states did not necessarily take a significant role in the maintenance of 'internal tranquility.' The point of Willer's argument is that judicious application of coercive efforts can bring a population under state domination without the necessity of an overcrowded population.

Scarcity of land need not be the only stimulus for state formation. Willer's formulation also provides for the possibility of an invasion of some prevailing system by some other force external to the system. The invasion can take place at nearly any point in the growth curve of the native population. Therefore, state development could begin prior to the point at which some region becomes overcrowded, i.e., the point at which overcrowding would lead to conflict over land.

Around the perimeter of cultivatable land there often are people who maintain themselves by hunting or herding. Given the highly mobile nature of these people's lifestyle, there can occur a rather high number of hostile encounters in a relatively large area of low population density. The encounters tend to occur for the same reasons as those among overcrowded agriculturalists-resource scarcity and concentration. The significant consequence of such repeated contracts is what Willer calls a 'culture of ferocity.' This culture of ferocity is generated and maintained by a system of normative convergence. It is manifested in an incerest of each member of a given group in having all other members of his group being highly fierce. For any 
individual nomad, being surrounded by people of intense ferocity insures his own survival. The insurance is manifested in being able to obtain necessities of survival in spite of scarcity, concentration, or competition. If any weak link in the armor is found, the interests of all others in the group converge and dictate the resolution of the problem through a variety of negative sanctions.

For those who live within a culture of ferocity it is possible to receive a wide range of negative sanctions with little or no preference-state alteration; i.c., all but the most extreme forms of coercion fail to change one's mind concerning some intended activity. This is due in part to their continual experience of 'minor' forms of negative sanctions. Such groups thus have the culture appropriate to ruling classes, but not to being ruled, due in part to their resistance to coercion. ${ }^{2}$

Thus, there is a potential of a culture of ferocity bordering the land of agriculturalists. It is not unlikely that these fierce peoples would have hostile encounters not only with others like themselves but also with agriculturalists near the edge of the workable land. Given a fully successful conflict with agriculturalists, the application of routinized coercion would result in a state. In short, the state would be a product of invasion from without, and not necessarily a result of conflict over land. In other circumstances, a series of less successful predations would result in the development of full-time defense units, at least among those at the edges of the agricultural land. In turn, these agriculturalists would become fierce and hostile toward others in the area and achieve the conditions of internal state development. The point is that over-population and land scarcity are not necessarily the only elements antecedent to a state. In this interpretation the state can develop by invasion or the threat of invasion.

\section{EVALUATION}

In order to determine the 'fit' of these theories to the case of the Hittites, evidence will be given concerning both the origin of the Hittites and the sequence of events leading up to state formation. 


\section{Origin}

Research by philologists indicates that it is unlikely that the original 'homeland' of the Indo-European languages was Anatolia. The Hittite language has been confirmed to be Indo-European. This means that the speakers of an Indo-European language such as the Hittites must have entered Anatolia from some other area (Macqueen, 1975).

General agreement on the linguistic evidence points to an Indo-European 'homeland' somewhere in the area that stretches from the lower Danube along the northern shore of the Black Sea to the northern foothills of the Caucasus. The question then concerns the route by which these people entered Anatolia. The possibilities are 1) the northwest via the Dardanelles and the Bosporus, or 2) from the northeast via the passes of the Caucasus. Several pieces of evidence support the northeastern route of migration as the one used by the Hittites for entry into Anatolia. According to John Garstang (1910:320-321) most scholars agree on a mountain origin for the Hittites. Two factors strongly suggest the mountains as the Hittite home. One is the footgear of the Hittites, which is always represented as a shoe or boot with upturned toe. This is commonly supposed to be the natural form of snow shoe for highland regions and is believed to be specially adapted to walking upon broken and stony ground. A further suggestion for the mountain origin is the dominance of mountain cults found in the Hittite pantheon. Garstand (1910) concludes that the mountains through which the Hittites reached the plateau of Asia Minor lie eastward in Armenia - the Caucasus. The key point here is that the environment of the pre-state Hittites was quite conducive to a culture of ferocity, and thus well-suited for a conquering and ruling class.

The Hittites arrived in Anatolia sometime around 2000 B.C. Given the Caucasus route, one of the first encounters of the Hittites with native Anatolians must lave been at or near the city of Divrigi. Divrigi was situated at the northern end of the Tigris-Euphrates river valleys. These valleys served as northern routes for the trading of tin from the east to the west, circumventing the land occupied by the Hurrians. In time, Divrigi 
was taken by the Hittites. The culture of ferocity, with its accompanying knowledge of military tactics, no doubt figured significantly in the take-over. Archeological evidence shows that after the initial take-over, the Hittites immediately undertook to subdue and dominate the surrounding area. The result was the establishment of the small state of Kussara (Macqueen, 1975).

The most important consequence of the establishment of the state of Kussara for the eventual establishment of a Hittite Empire was control of the only remaining tin routes between east and west. These routes went north of the Hurrian occupation. Control of these northern routes put the Hittites in a most commanding position with respect to the rest of Anatolia. Later the Hittites were to move south, presumably in scarch of control of the southern trading routes. The process of their expansion is the topic of the following section.

\section{The Hittite Process}

The Hittites apparently were greatly concerned with the costs of expansion and the problems of management. For example, they once advanced as far as Babylon and sacked it yet made no attempt to hold it as part of their empire. The process was fully routinized and rational.

Campaigning began in the spring with the melting of the deep snows in the Hittite homeland and generally continued throughout the summer months. In autumn the king returned to Hattusas to deal with diplomatic correspondence, hand down decisions on political cases, and consult with the city's governor on the administration of the capitol. In winter the king began his annual tour of provincial capitols. This served to keep him in touch with his empire. Most important were his religious duties as high priest of the land. This was necessary to keep the gods on his side Spring brought on another season of campaigns. (Hicks, 1974:99) 
The logic bchind this routine proved to be quite effective. By campaigning in the spring and summer, the highly effective Hittite army was able to encounter others while they were occupied with agricultural jobs. But why, it might be asked, were the Hittites not similarly occupied? The answer lies in the control of the Divrigi tin routes. By regulating the flow of goods through Divrigi, the Hittites could ensure that they would be well supplied at all times. And, through their superior military capabilities, the Hitrites could demand increased production from the lands they already controlled.

By returning to the capitol in the fall, the Hittites were ready for the annual paying of homage. With cyclic cropping that begins in the spring, the time for harvest is in the fall. Thus, it is during the fall that the coerced states are able to pay. At any other time the Hittites would undoubtedly meet with resistance due to the scarcity of surplus grains. By tapping the reserves at their fullest, two conditions are supported. First, there will be taxable produce. Second, and perhaps even more important, the perceived costs to those coerced are not as great as when there is less.

With the coming of winter the Hittite king left the capitol again, but this time not for military conquest; this time the campaign was political. Nearly every agricultural collectivity held some religious festival after the harvest was complete. Having the dual role of chief of state and chief priest of the land, the Hittitc king made the rounds of local festivals and presided over and participated in them. By appearing to take an interest in the local affairs, the Hittite monarch could reinforce his position and image among the real producers of the state.

\section{Potential us. Actual Coercion}

Evidence of the early expansion of the Hittite Empire indicates that superior military force was the prime mode of operation. However, in terms of empire-building and management costs, physical coercion alone proves quite costly. Thus, actual cocrcion had to give way to a more cost-conscious, yet similarly effective operation-potential coercion. 
Through earlier military campaigns the Hittite army had more than established themselves as a power capable of carrying out its intentions; they were feared. Thus, the threat of actual coercion served as the catalyst for further empire expansion and management. The usual procedure was to dispatch a letter demanding the extradition of Hittite subjects who had taken refuge in the enemy's territory. If the demand was refused, a second letter would follow, charging the enemy with having committed the first act of aggression and referring the affair to the judgment of heaven, to be settled by the ordeal of war (Gurney, 1952:114). Knowing of the military capabilities of the Hittites, at least three of their neighboring states apparently volunteered for Hittite vassalage (Hicks, 1974:73). In the cvent that subjugation was not so simple, then military operations were instigated. If surrender was offered by the enemy state and accepted by the Hittites no further action would be taken against the suppliant's territory. As a vassal, he would receive back his kingdom, a treaty would be drawn up, and he would undertake to perform all the specific duties required of him (Gurney, 1952:116). However, a city conquered by force of arms was generally looted and burned to the ground; the inhabitants of such a conquered place would be transplanted, with their catte, to Hattusas and distributed as serfs among the Hittite officers and dignitaries. It is significant that there is no evidence of ill treatment and cruelty (Gurncy, 1952:115).

Thus, there seems to have been a calm but powerfully persuasive tone in the expansion of the Hittite Empire. Even in the cases of cities taken by force, there was a tendency to maintain the status quo. An allegiance with a cooperative and loyal vassal was much more valued than physical dominance of an enemy. The costs of empire maintenance were thereby reduced for the Hittites by passing them on to the already established system. However, the reduced costs did not result in reduced production of the system; the threat of future action was still present if Hittite demands were not met. An interesting example of Hittite procedure is recounted in the story of Aitakama: 
Sutatara and his son Aitakama, with their war chariots, borc down upon him (Subbi-Juliuma) and gave battle. Though he was prepared to respect these adversaries, Subbi-luliuma was not slow to respond to punish this provocation; the king and his son, together with many of the chicfs, were taken prisoners and sent in triumph to the capitol. The fate of Sutatara is unknown, but Aitakama reappeared later, reinstated in his kingdom, and a faithful ally of the Hittites, who cntrusted him with command of the Syrian armics. (Garstang, 1931:331).

Historical accounts of the Hittites often refer to the above behavior as evidence of the intrinsic humaneness of the Hittite people. Humane though it may be, it is nonetheless calculated and rational. There are two negative results of continued use of force in conquest. First, as the empire expands, the costs of military campaigns to annex another area must reach a point of diminishing returns. It must be remembered that we are examining the second millennium B.C. with all of its limitations of transportation and communication. The sccond factor deals with the primary purpose of the conquest. The role of the state was not to invent new methods but to intensify existing means. If the Hittites were to "rape, pillage, and plunder," they would only hamper the ability of the conquered to produce the surplus desired. Further, to merely acquire land without a population to make it productive would only prove a burden to administration.

Thus potential coercion, not population density, was the means by which the empire was generated and expanded. It also served as the means by which the empire was administered. In the initial stages after acquisition, all vassals and satellite countries were glued to the Hittite Empire by written words. Treaties, a rarity at that time, outlined precisely the nature of the relationship between Hatti and the annexed land. Copies of the treaties were given to all involved parties (Hicks, 1974:74). The written word was then backed by certain pledges to the gods as witnesses. For the Hittites, the oath (treaty), with its solemn religious associations, was fundamental and was evidently regarded as a powerful sanction. The gods of both parties were usually 
involved for the religious outlook of the time was strongly national (Gurncy, 1952:75).

In the use of the gods as witnesses, the effort was to establish the threat of supernatural sanction in addition to the physical threat of the Hittite army. In so doing, the Hittites made the point that their gods were in fact superior to the local deities. The symbolic nature of these efforts is aptly shown in the formal presentation of the Hittite pantheon. In a massive wall carving just outside the capitol city, the two main Hittite gods are shown facing each other in larger than life stature. The other gods, smaller in size, are arranged behind one or the other Hitcite god with hands raised in submissive gestures. When shown this wall, vassal officials were in no doubt of their relationship to the Hittites, supernaturally or otherwise.

In order to make the system work and their threats effective, two tasks must be accomplished. First, the basic element of the ancient system, the peasant and the village must be reached by the threat. Second, once the peasant has been reached, the threat must reduce his altcrnative courses of action. This was done by making use of the dominance hierarchies already in existence In order to understand how this is accomplished, a model of the system will be of assistance.

The alternatives given the vassal lord were either to pay or be removed (which could mean' anything from execution to enslavement) and replaced. If the vassal lord agreed to pay, then it was left up to him to devise a means of extracting the payment from his own people. Generally the vassal lord had a similar relationship with the leaders of the villages in his domain. These leaders, the elders/priests, were given the same alternatives that the Hittites gave to the vassal lord. The goal was to stimulate more production from each village in order to make the payments to the Hittites.

In the model the elders/pricsts are secn as getting information from their own gods and passing it on to che peasants. In part, this information consists of advice on agricultural matters which will help increase production. In other instances this information consists of reminders of the vassal's relation to the Hittites-both earthly and spiritually. The relationship, of course, is that of the 
Mid-American Review of Sociology

FIGURE 1

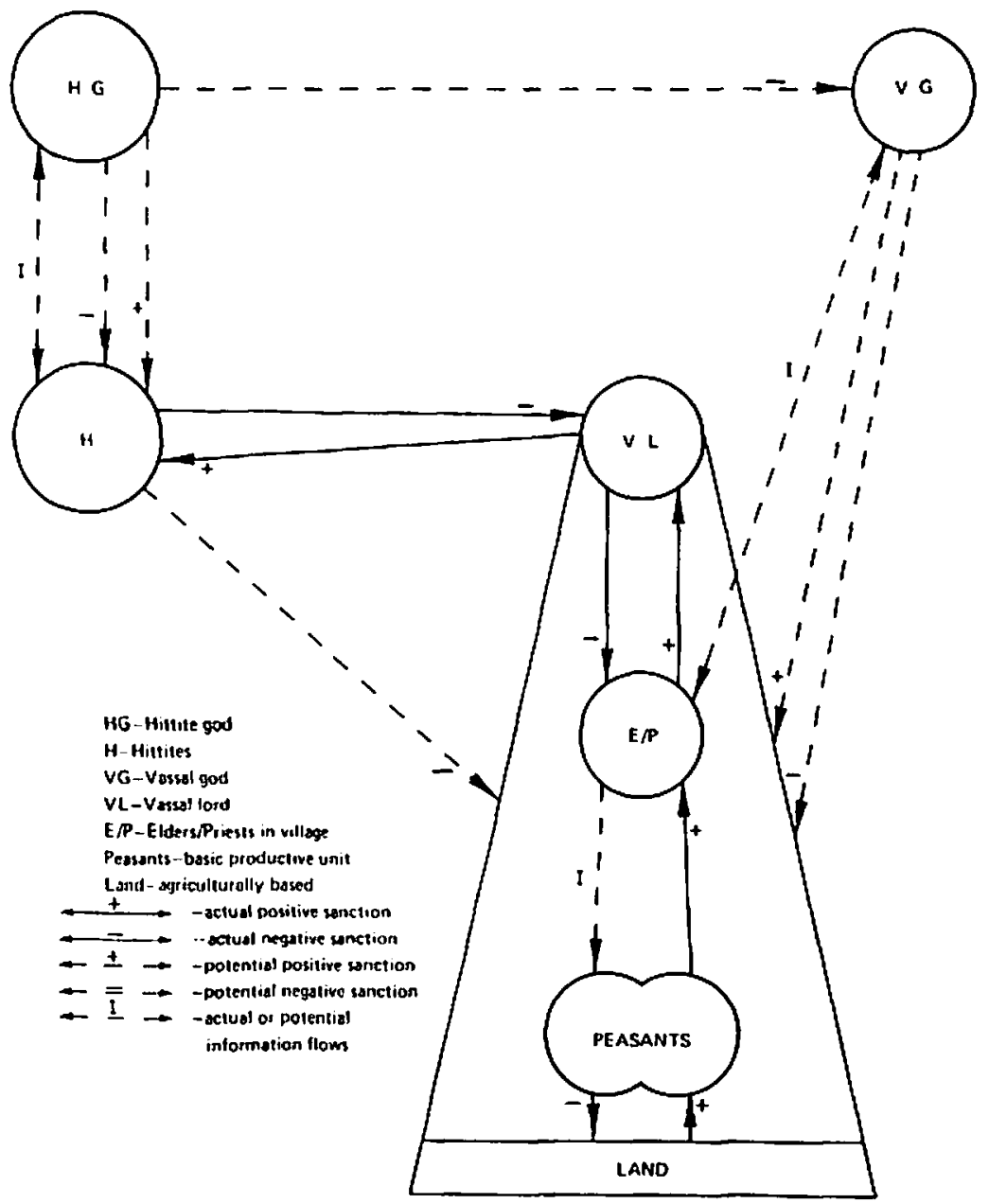


continuous potential threat. If the level of production in the village is too low, the potential threat may become actual.

The Hittite threat now reached the productive units-the peasants. This created a reduction of alternatives for the peasant. If he did not produce at a required level he knew that he would suffer sanctions from his gods, the vassal lord, the Hittites and their gods, etc. However, the system of dominance was designed such that an entire village was held responsible for its quota. Thus, the Hittites had brought into play the internal dynamics of a normative control system.

Given the alternatives available (and merely leaving the situation was not one which was available), any one peasant had a strong interest in every other peasant producing just as much as he possibly could. Thus, when any one pcasant failed to live up to production expectations, he was sanctioned-not by the elders/pricsts, the vassal lord, the Hittites, or the gods, but by his own status peers. In order to protect themselves, the peers made sure that the slow producer increased production or paid the consequences. In the cases of individual or small group resistance, those further up in the hierarchy rarely if ever had to exercise their coercive roles. As long as the belief system of the peasants was such that normative convergence (negative sanctioning by status peers) continued, the Hittites would eventually receive their payment and all others in the system would be maintained.

\section{CONCLUSION}

Although the Hittite Empire qualifies as a state according to Carnciro's own definition, it is obvious that the process of state development was quite different from the one Carneiro proposed. From the massive 'librarics of clay' which the Hittites left, we know that the Hittite state developed into a complex system of domination. From an initial invasion, the Hittites elaborated on the preceding system of organization among the city-states. The result was a rational and routinized system of dominance, developed and administered on the basis of potential coercion and manifested in the system of normative convergence on the village level. It is interesting to note that normative convergence was the 
mode of group existance of the nomadic period of the Hittite history. Its success was based on the capability of the Hittites to 1) actualize potential coercion, and 2) alter the belief system of its own population so that potential coercion need be actualized only occasionally.

With respect to Carneiro's interpretation, the focus on population densities has been shown to be unnecessary in the case of the Hitrites. The pre-Hittite system was incapable of achieving state status, as evidenced by the unsuccessful attempts of some cities to extend their domination. The stimulus for state development was external to the prevailing system; the Hittites invaded Anatolia. Had the population been overcrowded, according to Carnciro's theory, we would expect a state to have been in existance in Anatolia prior to Hittite contact. Thus it is concluded that potential coercion, rather than population density, was the motivating force.

Given that Willer's interpretation of external stimuli appears to explain the data rather accurately, the question now centers on the status of Carneiro's theory. The mark of a complete theory is that it can explain not only what has happened (history), but also what will happen (the future). Thus in certain cases, Carneiro's interpretation of state development is certainly adequate. However, the scope of his theory's application is quite narrow. The Hittite case shows that another interpretation may be nccessary. To conclude that Carneiro's theory has been disproven would be in error. To conclude that the case of the Hittites is more accurately interpreted by Willer's framework, based on his "elementary theory," is more proper.

\section{NOTES}

1. The major source for evidence on pre-Hittite Anatolia, when not otherwise cited, is Macqueen, 1975:1-21.

2. The Kaskans, a hunting tribe of the northern Anatolian mountains, provide a useful cxamplc. Though not an organized nation, the Kaskan warriors had been a thorn in Hatti's northern flank for more than $\mathbf{1 5 0}$ 
years. For those 150 years, the Kaskans kcpt the empire's northern border continually in turmoil. Even at the height of Hittite expansion, the boundary of effective Hittite control rarely extended more than a few dozen miles north of the capital city of Hattusas. Sometime around 1300 B.C., when the Hittites' energies were absorbed elsewhere, the Kaskans cven managed to penetrate Hattusas' defenses and plunder the city. The occupation was only temporary, but the role of the Kaskan's culture of ferocity was nonetheless most significant. (Hicks, 1974:143).

\section{REFERENCES}

Carneiro, Robert L.

1970 "A Theory of the Origin of the State," Science 169:733-738.

Garstang, John

1910 The Land of the Hittites. London: Constable and Co., Lid. Gurney, O.R.

1954 The Hittites. Baltimore: Penguin Books, Inc.

Hicks, Jim

1974 The Empire Builders. New York: Time-Life Books. MacQueen, J.G.

1975 The Hittites. Boulder, Colorado: Westview Press, Inc. Willer, David

1977 "A Network Interpretation of Carneiro's Theory of the Origin of the State," Paper presented at the annual meeting of the American Anthropological Society, Houston, Texas. 